\title{
Toluene Abatement by Non-Thermal Plasma Coupled with Thin Film of Cu-Co Binary Oxide Coated on Stainless Steel Mesh
}

\author{
Dan Yu ${ }^{1}$, Zhenyu Tian ${ }^{1,2 *}$, Muhammad Waqas ${ }^{1,2}$, Zhihao Jin ${ }^{1,2}$, Achraf El Kasmi', Dongxu Tian ${ }^{1,2}$ and Patrick Mountapmbeme Kouotou ${ }^{1,3}$
}

Toluene abatement has been investigated with a plasma catalytic technique without additional heating. Thin film of the Cu-Co binary oxide was coated on stainless steel mesh (SSM). The prepared $\mathrm{Cu}-\mathrm{Co}-\mathrm{O} / \mathrm{SSM}$ was located in two annular dielectric barrier discharge (DBD) reactors. Toluene removal exhibits two-stage characteristics in the $60-\mathrm{mm}$ DBD reactor. In the first stage, both full locating SSM and Cu-Co-O /SSM could equally improve the toluene removal, indicating that SSM dominates the catalytic role on toluene conversion resulting from its conductivity. In the second stage, $\mathrm{Cu}-\mathrm{Co}-\mathrm{O} / \mathrm{SSM}$ could improve the complete conversion of toluene, as the specific energy density is above $153 \mathrm{~J} / \mathrm{L}$ by providing a reactive surface. Toluene removal exhibits one stage characteristics in the 200-mm DBD reactor. The removal efficiency and $\mathrm{CO}_{2}$ selectivity could respectively achieve $100 \%$ and $64 \%$ as the specific energy density being around $20 \mathrm{~J} / \mathrm{L}$. Partial locating $\mathrm{SSM}$ or $\mathrm{Cu}-\mathrm{Co}-\mathrm{O} / \mathrm{SSM}$ could equally improve the complete toluene conversion as the specific energy density being above $8 \mathrm{~J} / \mathrm{L}$. Cu-Co-O thin film has negligible effect on toluene conversion. The gas and surface reaction mechanism has been proposed. Specific energy density and locating pattern could influence the effect of $\mathrm{Cu}-\mathrm{Co}-\mathrm{O}$ thin film coated on SSM.

Keywords: $\mathrm{Cu}-\mathrm{Co}-\mathrm{O}$ thin film; Toluene; Non-thermal plasma; Two-stage removal; Surface reaction

Received 24 January 2019, Accepted 2 Jun 2019

DOI: $10.30919 / \mathrm{esee} 8 \mathrm{c} 301$

\section{Introduction}

As a typical component of volatile organic compounds (VOCs), toluene causes respiratory disorders, carcinogenic and mutagenic effects. ${ }^{1}$ Since it is difficult to be abated due to the presence of $\pi$-electron ring, toluene is usually selected as a probe contaminant for the treatment of VOCs. Many methods have been adopted to abate toluene. Recently, an innovative technique, named plasma-catalysis, has attracted much attention in the environmental and chemical engineering fields. Such technique integrates the advantages of quick response at room temperature from non-thermal plasma and high selectivity of desired products from catalysis. ${ }^{24}$ Therefore, plasma-catalysis has the prospect of application in an industrial scale.

Lots of work has been performed on the abatement characteristics of toluene, using various catalysts. Most of them are supported metals or metal oxides. ${ }^{5-10}$ The active components were usually $\mathrm{Ag},{ }^{11} \mathrm{Co},{ }^{10} \mathrm{MnO}_{\mathrm{x}},{ }^{6,12} \mathrm{CuO}_{\mathrm{x}},{ }^{13} \mathrm{CoO}_{\mathrm{x}},{ }^{12} \mathrm{VO}_{\mathrm{x}}{ }^{14}$ and etc. The supports were reported to be highly porous and thermostable materials, providing high surface area and suitable mechanical strength, such as metal oxide particles, ${ }^{15}$ activated carbons, ${ }^{6,}{ }^{16}$ molecular sieves, ${ }^{15}$ honeycomb, ${ }^{14}$ sintered metal fibers, ${ }^{12}$ or conjugated polymers. ${ }^{17}$ Among these catalysts, $\mathrm{CuO}$ is very active for removal of exhaust gases with comparable

'Institute of Engineering Thermophysics, Chinese Academy of Sciences, Beijing 100190, China

${ }^{2}$ University of Chinese Academy of Sciences, Beijing 100049, China

${ }^{3}$ National Advanced School of Engineering of Maroua, University of

Maroua, P.O. Box.: 46 Maroua, Cameroon

*E-mail: tianzhenyu@iet.cn performance to the noble metals. ${ }^{5,18}$ It has been used in the removal of toluene and other VOCs with attractive performance. ${ }^{19,20}$ However, $\mathrm{CuO}$ presents a limited stability during catalytic oxidation. It was recently reported that the introduction of $\mathrm{Co}$ into $\mathrm{CuO}$ structure could significantly improve the catalytic activity and stability of the binary oxide. ${ }^{8}$ Thus, the synthesis of $\mathrm{Cu}-\mathrm{Co}$ binary oxide $(\mathrm{Cu}-\mathrm{Co}-\mathrm{O})$ catalyst is expected to provide beneficial effect on toluene conversion using plasma. Besides improving the quality of the active component, reducing its quantity is also a key issue in the plasma catalysis research. In previous studies, weight percentage of the active component in the supported catalyst is usually larger than $3 \%$. For example, in the study of $\mathrm{Xu}$ et al., ${ }^{10}$ the weight percentage of cobalt is about $3.4 \%$ in the catalysts of $\mathrm{Co} / \mathrm{MCM}-41$. Performance of the active catalyst with small quantity is highly desirable.

Catalyst, in the plasma zone, usually plays the catalytic effect through two ways, providing a reactive surface and modifying the plasma properties from the physical and chemical aspects. ${ }^{21-24}$ It is difficult to study the two parts separately by the experimental method, since they are coupled in the inner plasma-catalyst system. The mutual interactions between plasma and catalyst, possibly giving rise to the synergistic mechanism in the plasma-catalysis, are urgently needed to be elucidated. Till now, a large number of experimental and theoretical studies have been referred to the effect of catalyst on the plasma and vice versa. ${ }^{25}$ Nevertheless, the exact mechanisms of the catalyst effect on the toluene removal, in plasma zone, remain unclear.

In this work, thin film of $\mathrm{Cu}-\mathrm{Co}-\mathrm{O}$ was coated on the stainless steel mesh (SSM) via pulsed-spray evaporation chemical vapor deposition (PSE-CVD) method, ${ }^{26,27}$ which is a facile, direct and inexpensive technique to synthesize the continuous thin film catalyst 
with high purity. Two annular dielectric barrier discharge (DBD) reactors with different plasma length were home-designed and coupled with the prepared $\mathrm{Cu}-\mathrm{Co}-\mathrm{O} / \mathrm{SSM}$ as the full and partial locating pattern, respectively. The characteristics of the toluene removal has been studied based on the comparison experiments between the two catalyst-locating pattern and among plasma, plasma-SSM and plasma-Cu-Co-O/SSM configurations. The interaction between catalyst and plasma has been also inferred. The mechanism in the gas phase and on the surface phase was proposed.

\section{Experimental}

\subsection{Preparation of $\mathrm{Cu}-\mathrm{Co}-\mathrm{O}$ thin film}

$\mathrm{Cu}-\mathrm{Co}-\mathrm{O}$ thin film was coated on a piece of round SSM with the diameter of $60 \mathrm{~mm}$ by a cold-wall stagnation point flow PSE-CVD reactor. Details of the setup and experimental procedure had been illustrated in our previous works $\mathrm{s}^{28,29}$ and only a brief description is given here. A mixture of copper acetylacetonate $\left(\mathrm{Cu}(\mathrm{acac})_{2}\right)$ and cobalt acetylacetonate $\left(\mathrm{Co}(\mathrm{acac})_{2}\right)$ as precursors dissolved in ethanol solutions $(5 \mathrm{mM})$ was optimized with $3 / 7$ molar ratio of $\mathrm{Cu} / \mathrm{Co}$ and used as the liquid feedstock. The liquid delivery allows overcoming the inherent contrast between the sticking probabilities of different precursors in the dual-source strategy for the growth of multi-component films. The PSE delivery of the blended feedstock was achieved with a valve opening time of $1 \mathrm{~ms}$ and a frequency of $4 \mathrm{~Hz}$. The evaporation of the injected feedstock took place at $200{ }^{\circ} \mathrm{C}$. The resulting vapor was transported to the deposition chamber with $\mathrm{O}_{2}$ and $\mathrm{N}_{2}$ flow rates of 0.50 and 0.25 standard liter per minute (SLM) process. The SSM was. During the deposition process, the SSM, with 400 holes per square inch, was heated to $320^{\circ} \mathrm{C}$ by a flat resistive heater, and the total pressure in the reactor was kept at 20 mbar. $\mathrm{Cu}-\mathrm{Co}-\mathrm{O}$ thin film was also coated on a piece of square glass with the length of a slide being $10 \mathrm{~mm}$ using the similar PSE-CVD method at the exactly same condition. The $\mathrm{Cu}-\mathrm{Co}-\mathrm{O}$ thin film/glass was used for the later X-ray diffraction (XRD) detection.

\subsection{Characterization of $\mathrm{Cu}-\mathrm{Co}-\mathrm{O}$ thin film}

The prepared $\mathrm{Cu}-\mathrm{Co}-\mathrm{O}$ thin film were characterized by several techniques. The phase and structure of the prepared binary oxide catalyst were analyzed by XRD (Phillips X'Pert Pro MDR diffractometer with $\mathrm{PW} 3830$ X-ray generator, $\mathrm{Cu} \mathrm{K} \alpha$ radiation, $\lambda$ $=0.154056 \mathrm{~nm})$ ) method. The surface morphologies of the prepared catalyst before and after plasma-catalysis experiments were detected by field-emission scanning electron microscope (SEM, Hitachi S-4800) and energy dispersive spectrometer (EDS). The four-point probe method using the DC current supplier was performed to measure the conductivities of the SSM and $\mathrm{Cu}-\mathrm{Co}-\mathrm{O} / \mathrm{SSM}$ at the room temperature and ambient pressure.

\subsection{DBD reactor}

Schematic diagram of the DBD reactor is shown in Fig. 1a. The reactor is mainly composed of a quartz tube $(\mathrm{OD}=10 \mathrm{~mm}, \mathrm{ID}=8 \mathrm{~mm})$ with the length of $400 \mathrm{~mm}$. A SSM, without $\mathrm{Cu}-\mathrm{Co}-\mathrm{O}$ thin film, was rolled outside of the tube and connected to the high-voltage electrode, and a $30-\mathrm{mm}$ stainless steel stick ( $\mathrm{SSS}, \mathrm{OD}=6 \mathrm{~mm}$ ) was coaxially located inner the tube and connected to the low-voltage electrode. Two homedesigned rod supports with four similar prominences, as shown in Fig. $1 \mathrm{~b}$, were used to keep the SSS coaxial with the silica tube and the gas passing through the tube smoothly. Distance of the discharge gap was 1 $\mathrm{mm}$. Two sizes of the discharge zones, 60 and $200 \mathrm{~mm}$ length, were applied. The prepared $\mathrm{Cu}-\mathrm{Co}-\mathrm{O} / \mathrm{SSM}$ was inserted into the space between the inner electrode and silica tube. Two configuration patterns, full and partial patterns, were obtained as the $\mathrm{Cu}-\mathrm{Co}-\mathrm{O} / \mathrm{SSM}$ located in the former two DBD reactors. For the comparison study, six configurations, listed in Table 1, were used in the experiment. The DBD reactor was fed with the $6-8 \mathrm{kHz}$ frequency AC power supply in the voltage range of $0-4 \mathrm{kV}$ (Coronalab CTP-2000K). For the inner plasmaSSM (IPS) and inner plasma-CuCoO/SSM (IPC) configurations, the round SSM without and with thin film $\mathrm{Cu}-\mathrm{Co}-\mathrm{O}$ catalyst respectively, was rolled and put in the discharge gap.

\subsection{Electrical diagnostics}

An electrical diagnostics system, as shown in Fig. 1c, was employed to measure the discharge power of the plasma reactor. The $V-Q$ Lissajous figure method was adopted to determine the discharge power in the plasma reactor. A capacitor of $33 \mathrm{nF}$ connected in series to the ground line of the plasma reactor was used. The high voltage applied to the plasma reactor was obtained with a 1000:1 high voltage probe (Tektronix, P6015A). The voltage across the capacitor, which was proportional to the charge Q (time-integrated current), was recorded with a 10:1 passive probe (Tektronix, TPP0101). The voltage and frequency signals were detected by a digitizing oscilloscope (Tektronix, DPO2024B).

\subsection{Experimental procedure}

The whole experimental setup is composed of a DBD reactor, a thin film $\mathrm{Cu}-\mathrm{Co}-\mathrm{O}$ catalyst, a power supply, an electrical signal diagnostic system, a gas supply system and a gas analysis system. The initial

Table 1 Six configurations used in the experiments.

\begin{tabular}{ccc}
\hline Configuration & Length of plasma region $(\mathbf{m m})$ & Catalyst in the plasma region \\
\hline P-60 $^{\mathbf{a}}$ & 60 & None \\
IPS-60 $^{\mathbf{b}}$ & 60 & $\mathrm{SSM}$ \\
IPC-60 $^{\mathbf{c}}$ & 60 & $\mathrm{Cu}-\mathrm{Co}-\mathrm{O} / \mathrm{SSM}$ \\
P-200 $^{\mathbf{a}}$ & 200 & $\mathrm{None}$ \\
IPS-200 $^{\mathbf{b}}$ & 200 & $\mathrm{SSM}$ \\
IPC-200 $^{\mathbf{c}}$ & 200 & $\mathrm{Cu}-\mathrm{Co}-\mathrm{O} / \mathrm{SSM}$
\end{tabular}

Note: ${ }^{a}$ the configuration of only plasma, without any SSM or Cu-Co-O/SSM in the plasma region; ${ }^{b}$ the configuration of plasma-SSM, with $\mathrm{SSM}$ in the plasma region; ${ }^{\mathrm{c}}$ the configuration of plasma-Cu-Co-O/SSM, with $\mathrm{Cu}-\mathrm{Co}-\mathrm{O}$ thin film coated on the SSM in the plasma region. 
concentration of toluene was kept to be $231 \mathrm{ppm}$, which was obtained by controlling the flow rate of the toluene standard gas, the carrier gas argon and the oxygen flows. After passing through a mixing chamber, the fed gas entered the DBD reactor. The total gas flow rate was controlled to be 0.215 SLM, corresponding to the gas hourly space velocity (GHSV) of 2,150 L $\cdot \mathrm{g}^{-1} \mathrm{~h}^{-1}$. Outlet profiles of toluene, $\mathrm{CO}_{2}$ and $\mathrm{CO}$ were detected by absorption FTIR. ${ }^{8}$ The gaseous organic byproducts were analyzed by a GC-MS (Aglient 7890B-5977A, USA) and GC (Aglient 7890B, USA) equipped with three capillary columns (Molecular Sieve-5A, $\mathrm{Al}_{2} \mathrm{O}_{3}-\mathrm{KCl}$ and HP-INNOWax), TCD and FID. The specific energy density (SED), defined as discharge power/gas flow rate $(\mathrm{J} / \mathrm{L})$, was used to normalize the flowrate difference. Toluene conversion (TC) and $\mathrm{CO}_{2}$ selectivity (CS) were used to characterize the removal of toluene. TC is defined to be $\left(\mathrm{C}_{\text {in }}-\mathrm{C}_{\text {out }}\right) / \mathrm{C}_{\text {in, }}$, where $\mathrm{C}_{\text {in }}$ and $\mathrm{C}_{\text {out }}$ are the inlet and outlet concentrations of toluene, respectively. $\mathrm{CS}$ is defined as the expression of $\mathrm{C}_{\mathrm{CO} 2} /\left(\mathrm{C}_{\mathrm{CO} 2}+\mathrm{C}_{\mathrm{CO}}\right)$, where $\mathrm{C}_{\mathrm{CO} 2}$ and $\mathrm{C}_{\mathrm{CO}}$ are the concentrations of $\mathrm{CO}_{2}$ and $\mathrm{CO}$, respectively.

\section{Results and discussion}

3.1 Characteristics of $\mathrm{Cu}-\mathrm{Co}-\mathrm{O}$ thin film
The weight of the Cu-Co-O thin film is $3.09 \mathrm{mg}$, which is only $0.7 \%$ of that of the $\mathrm{Cu}-\mathrm{Co}-\mathrm{O} / \mathrm{SSM}$ catalyst $(441.43 \mathrm{mg})$. This weight ratio value is $21 \%$ lower than those in the previous studies. ${ }^{10}$ The thickness of the $\mathrm{Cu}-\mathrm{Co}-\mathrm{O}$ thin film is estimated to be $\sim 160 \mathrm{~nm}$. The XRD pattern of the catalyst coated on glass at $320{ }^{\circ} \mathrm{C}$ is shown in Fig. 2. The characteristic peaks of $\mathrm{Cu}-\mathrm{Co}-\mathrm{O}$ film display in excellent agreement with those of $\mathrm{Co}_{3} \mathrm{O}_{4}$ (JCPDS No. 74-1656) and $\mathrm{CuO}$ (JCPDS No. 48-1548). More importantly, no extra diffraction peaks associated with the presence of impurities or any other phases were detected. The prepared $\mathrm{Cu}-\mathrm{Co}-\mathrm{O}$ thin film was a mixture of cubic $\mathrm{Co}_{3} \mathrm{O}_{4}$ and $\mathrm{CuO}$ with high purity. The micro-strain and crystalline size of the oxides were calculated by

$$
\varepsilon=\beta / 2 \cot \theta
$$

and by applying the Scherrer equation

$$
\mathrm{D}=0.9 \lambda / \beta \cos \theta
$$

to the most intense diffraction peaks, respectively, where $\lambda=0.154056$ $\mathrm{nm}$ and where $\beta$ and $\theta$ respectively represent the full width at half

(a)

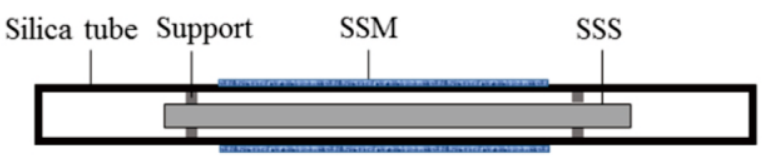

(b)

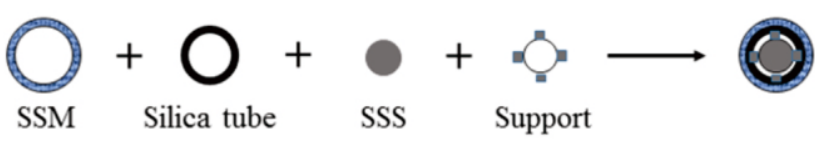

(c)

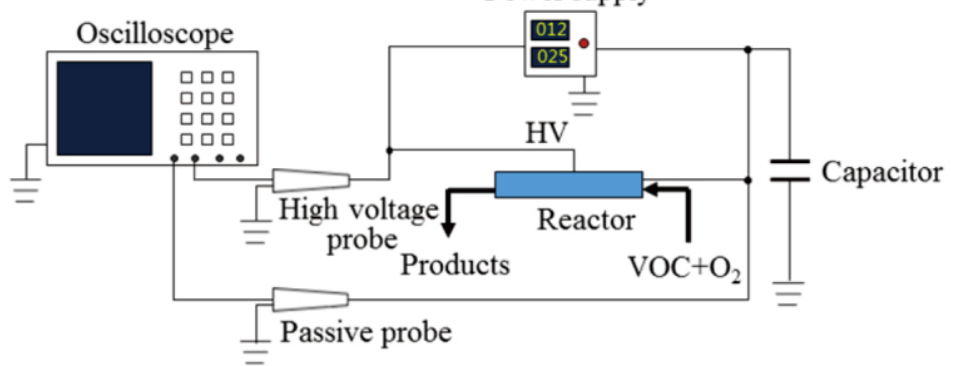

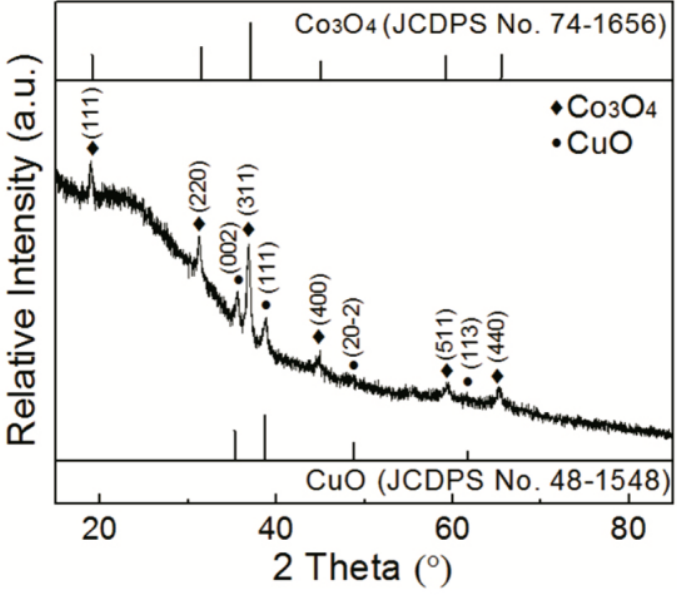

Fig. 2 XRD pattern of the $\mathrm{Cu}-\mathrm{Co}-\mathrm{O}$ thin film.

Fig. 1 Schematic diagrams of (a) plasma-catalysis reactor, (b) transversal surface of the reactor and (c) electrical diagnostics system.
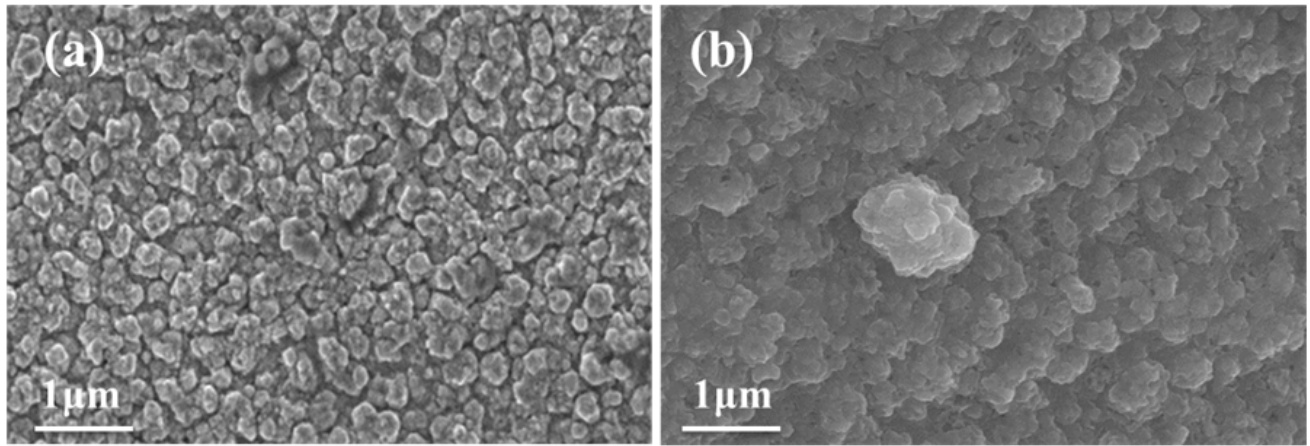

Fig. 3 SEM results of (a) the fresh $\mathrm{Cu}-\mathrm{Co}-\mathrm{O}$ thin film and (b) that after the IPC experiment. 
maximum (FWHM) and diffraction angle of the observed peak. The crystal size of prepared catalyst was estimated to be $17 \pm 3 \mathrm{~nm}$ and micro stain $\varepsilon$ was $0.176 \% \pm \mathrm{X}$, which is in good agreement with literature. $^{29}$

The surface morphology of the prepared catalyst before and after plasma-catalysis experiment are shown in Fig. 3. In general, smooth and evenly distributed uniform particles were observed in both cases. The particle size was estimate to be $\sim 18 \mathrm{~nm}$, which matches well with the calculated value from XRD analysis. This highly dispersed morphology with small particle size could produce more active sites to hold the adsorbed oxygen and be beneficial to the catalytic application in the plasma-catalysis system.

The EDS data of the fresh thin film catalyst and that after the IPC experiment are listed in Table 2 . The $\mathrm{Co} / \mathrm{Cu}$ weight ratios before and after the IPC experiment are similar to be 1.26. The carbon and oxygen elements reduce much after the plasma-catalyst experiment. It means that these two atoms join the toluene removal process in the electric field.

\subsection{Characteristics of plasma discharge}

Fig. $4 \mathrm{a}, \mathrm{b}$ and $\mathrm{c}$ show the Lissajous figures under different input voltages of the power supply $\left(\mathrm{U}_{\mathrm{i}}\right)$ in P-200, IPS-200 and IPC-200 configurations, respectively. The shapes of DBD Lissajous figures are approximate parallelograms. The areas of parallelogram increase with increasing of $\mathrm{U}_{\mathrm{i}}$, indicating that the DBD power increases with increasing of $U_{i}$. Adding SSM in the plasma region could influence the shape of parallelogram under the similar $U_{i}$, compared with P-200. The parallelogram area of IPS-200 is a little larger than that of P-200 as $U_{i}$ is larger than $1.2 \mathrm{~V}$. As shown in Fig. 4b, DBD power of IPS-200 is larger than that of P-200 under the similar $\mathrm{U}_{\mathrm{i}}$, in the range of 1.2-3.0 V. The parallelogram shape of IPC-200 (Fig. 4c) is similar to that of IPS-200. However, the parallelogram area of IPC-200 is slightly smaller than that of IPS-200 but still larger than that of P-200. In the region of 1.2-3.0 V, DBD power of IPC-200 is larger than that of P-200 but less than IPS200 under the similar $U_{i}$. When $U_{i}$ is in the range of $0-1.2 \mathrm{~V}$, the DBD powers for P-200, IPS-200 and IPC-200 are similar.

The Lissajous figures under $\mathrm{U}_{\mathrm{i}}=2.1 \mathrm{~V}$ in P-60, IPS-60 and IPC-60 configurations are shown in Fig. 5. The DBD Lissajous figures keep parallelogram shape. Adding SSM or $\mathrm{Cu}-\mathrm{Co}-\mathrm{O} / \mathrm{SSM}$ in the plasma region could influence the shape of parallelogram. As shown in Fig. 6a, in the $U_{i}$ scale of $0-1.2 \mathrm{~V}$, DBD power is similar for the P-60, IPS-60 and IPC-60. As the $U_{i}$ is in the scale of 1.2-2.4 V, DBD power follows the sequence of P-60>IPC-60>IPS-60. When the $\mathrm{U}_{\mathrm{i}}$ is above $2.4 \mathrm{~V}$, DBD power follows the sequence of IPC-60 $>$ IPS-6 $>$ P- 60 . The SED for the short plasma region is much larger than that for the longer plasma region under the similar $\mathrm{U}_{\mathrm{i}}$.

Fig. 6 shows SED vs the applied voltage, U. For the fullylocating pattern, the SED are similar for the three configurations, P-60, IPS-60 and IPC-60 as the U is below $1000 \mathrm{~V}$. The SED for one

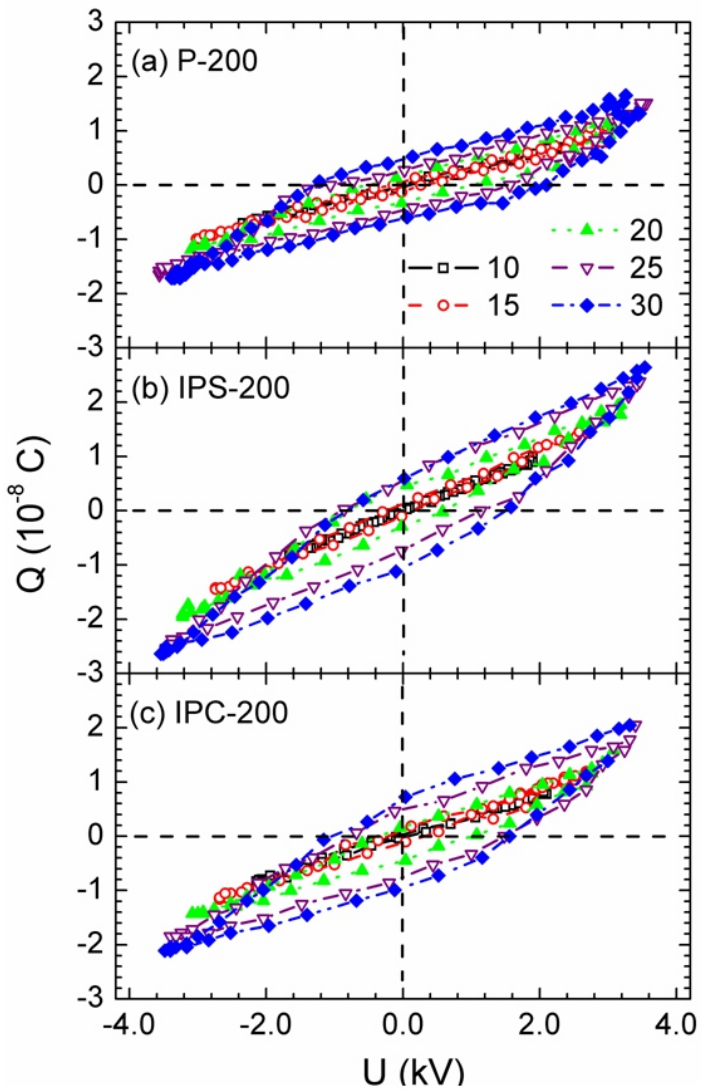

Fig. 4 Lissajous figures for the discharge gap of $1 \mathrm{~mm}$ for the input voltages of the power supply $10,15,20,25$ and $30 \mathrm{~V}$ as the length of the plasma region being $200 \mathrm{~mm}$.

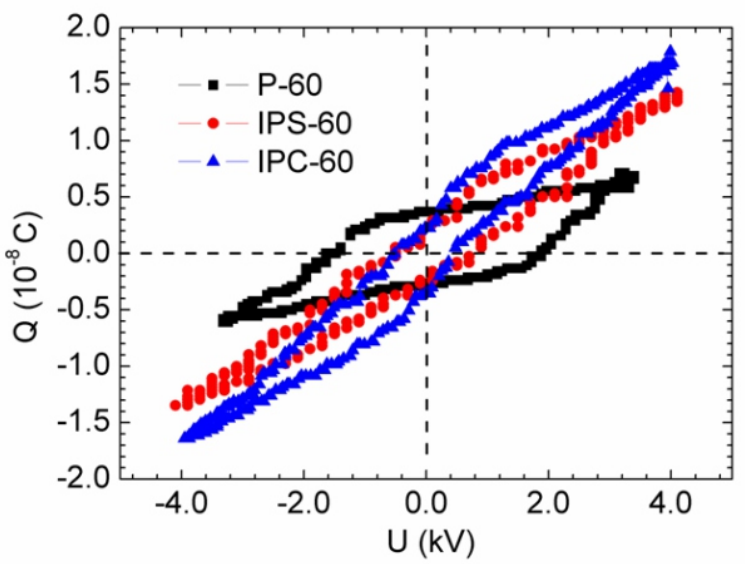

Fig. 5 Lissajous figures for the discharge gap of $1 \mathrm{~mm}$ for the input voltages of the power supply $21 \mathrm{~V}$ as the length of the plasma region being $60 \mathrm{~mm}$.

Table 2 EDS results of the fresh $\mathrm{Cu}-\mathrm{Co}-\mathrm{O}$ thin film and that after the IPC experiment.

\begin{tabular}{ccc}
\hline \multirow{2}{*}{ Element } & \multicolumn{2}{c}{ Wt \% } \\
\cline { 2 - 3 } & Before the experiment & After the experiment \\
\hline $\mathrm{Co}$ & 18.44 & 41.95 \\
$\mathrm{Cu}$ & 14.62 & 32.97 \\
$\mathrm{O}$ & 39.34 & 16.55 \\
$\mathrm{C}$ & 27.60 & 8.53 \\
\hline
\end{tabular}


condition was calculated for three times. The average one was used as the SED. The error of the SED is with $20 \%$, because of the calculation process. The error is larger especially for the low voltage.

\subsection{Fully-located pattern}

For the DBD reactor with 60-mm plasma region, round piece of SSM or $\mathrm{Cu}-\mathrm{Co}-\mathrm{O} / \mathrm{SSM}$ with the diameter of $60 \mathrm{~mm}$, could be fully located in the plasma region. Fig. 7 illustrates the TC, derivatives of toluene conversion (DTC) and CS in various configurations for this DBD reactor.

As shown in Fig. 7b, DTC curves for P-60, IPS-60 and IPC-60 present two peaks, indicating that the toluene abatement process could be divided into two stages as the $\mathrm{U}_{\mathrm{i}}$ or SED increases. In the first stage, toluene conversion firstly increases abruptly and then reaches plateau at $56 \%, 67 \%$ and $70 \%$ for the P-60, IPS-60 and IPC-60, respectively. In this stage, the concentration of $\mathrm{CO}_{2}$ keeps lower than that of $\mathrm{CO}$, and both of them increase as the SED increases.

In the first stage, the CS increases as the SED increases firstly, and then keeps stable at $26 \%, 31 \%$ and $35 \%$ for the P-60, IPS-60 and IPC60, respectively, as shown in Fig. 8. In the second stage, TC restarts to increase abruptly. They could respectively achieve $32 \%, 40 \%$ and $75 \%$ at $\mathrm{SED} \approx 120 \mathrm{~J} / \mathrm{L}$, for the P-60, IPS-60 and IPC-60. Cu-Co-O thin film could improve the toluene conversion in the second stage significantly.

In the first stage, toluene starts to convert at $5 \mathrm{~J} / \mathrm{L}$, and achieves $50 \%$ conversion at $24 \mathrm{~J} / \mathrm{L}$ in the P-60 configuration, as shown in Fig. 9. Adding $\mathrm{SSM}$ or $\mathrm{Cu}-\mathrm{Co}-\mathrm{O} / \mathrm{SSM}$ in the plasma region could equally improve TC to achieve $50 \%$ conversion at $9 \mathrm{~J} / \mathrm{L}$, which is much lower than that in P-60. SSM plays a catalytic role on TC, while, $\mathrm{Cu}-\mathrm{Co}-\mathrm{O}$ thin film has negligible effect. Since SSM is a conductor, it could

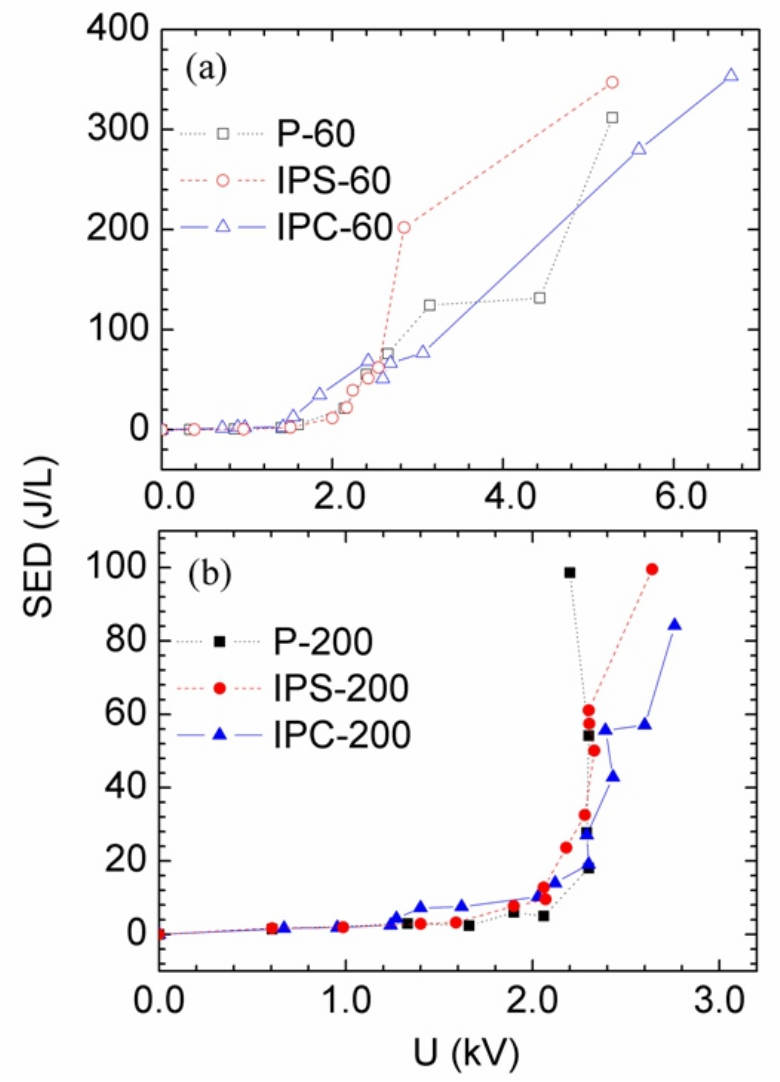

Fig. 6 Specific energy density versus applied voltage in P, IPC and IPS configurations as the length of the plasma region being 60 and $200 \mathrm{~mm}$. influence the characteristics of the plasma discharge. From Fig. 5, the Lissajous curve shows that adding SSM could change the discharge characteristics significantly. Therefore, the toluene removal for IPS-60 is improved, compared with P-60. It should be noted that the Lissajous curve of IPC-60 is quite similar to that of IPS-60. SSM could be an inner electrode in the plasma reactor due to its good conductivity. The coating of $\mathrm{Cu}-\mathrm{Co}-\mathrm{O}$ thin film could influence the conductivity of SSM. As listed in Table 3, the resistivity of $\mathrm{Cu}-\mathrm{Co}-\mathrm{O} / \mathrm{SSM}$ is twice as that of SSM. Coating of $\mathrm{Cu}-\mathrm{Co}-\mathrm{O}$ thin film on SSM could reduce its conductivity. However, it could not change it to a dielectric material. Moreover, the $\mathrm{Cu}-\mathrm{Co}-\mathrm{O}$ film has scarce influence on the shape of the

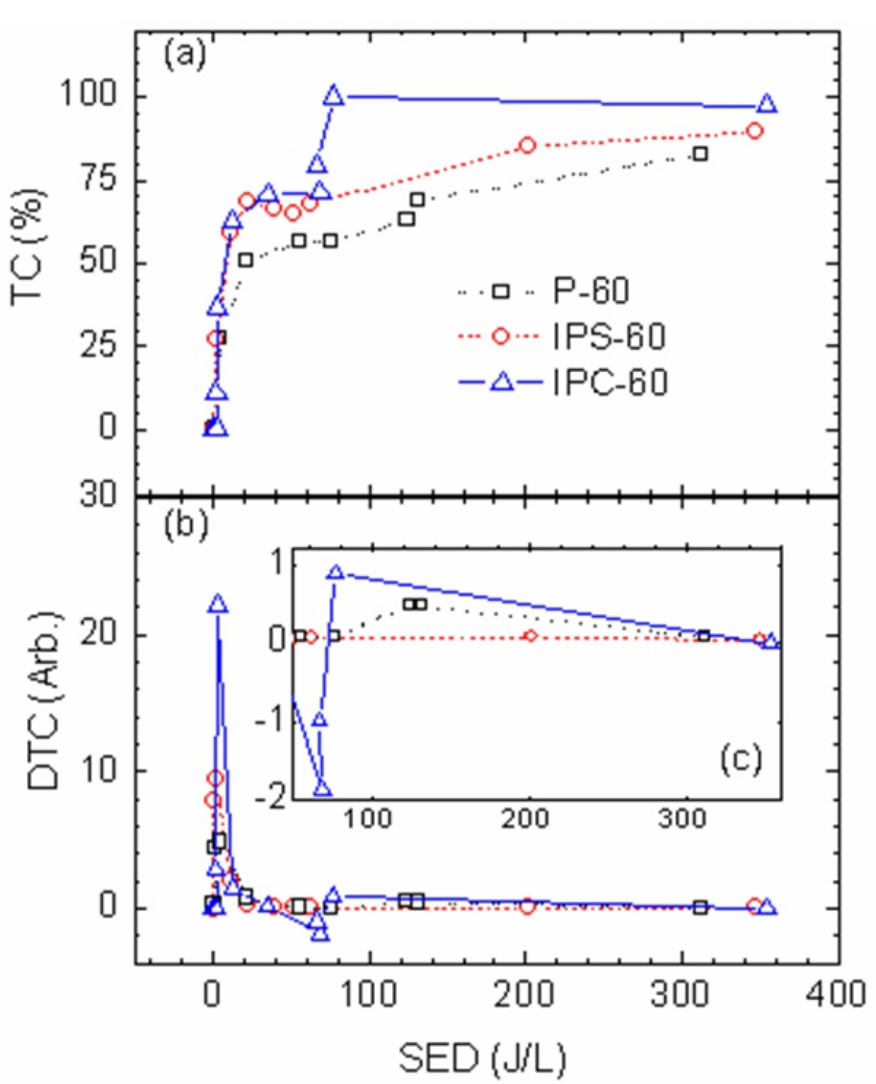

Fig. 7 (a) Toluene conversions, and (b) derivatives of toluene conversion in various configurations.

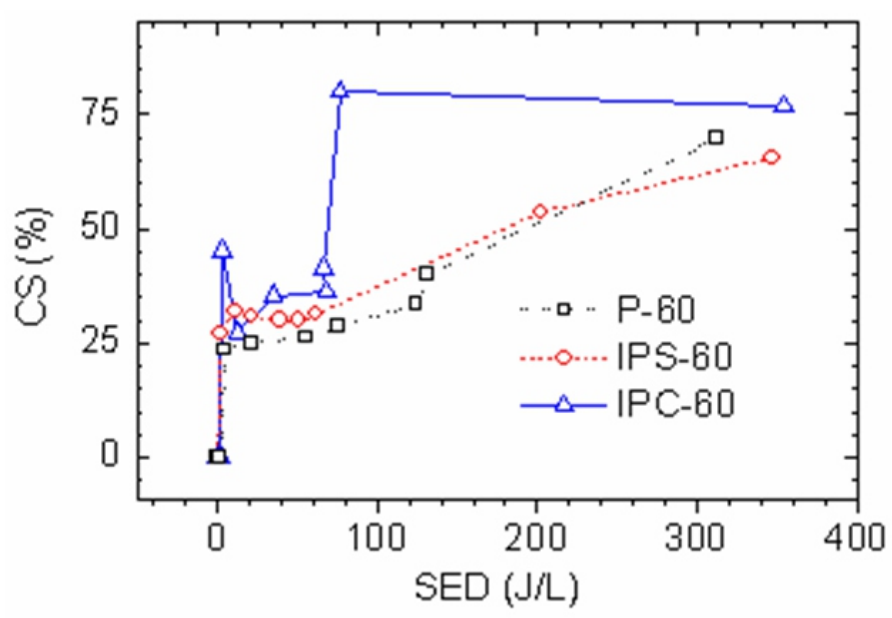

Fig. $8 \mathrm{CO}_{2}$ selectivity in various configurations. 
substrate due to its thickness as thin as $160 \mathrm{~nm}$. Introduction of a piece of SSM, either coated or non-coated with the binary oxide, in the plasma region could equally act as an inner electrode and result in the reduction of the discharge gap dramatically. Therefore, the SSM plays a catalytic effect in this stage. Considering the CS follows the sequence of IPC-60>IPS-60>P-60 in the latter part of the first stage, $\mathrm{Cu}-\mathrm{Co}-\mathrm{O}$ thin film has an little catalytic effect on the CS, but ignorable catalytic effect on TC in the first stage.

In the second stage, TC follows the sequence of IPC-60>IPS$60>\mathrm{P}-60$ at similar $\mathrm{U}_{\mathrm{i}}$. The $\mathrm{CS}$ in IPC-60 exhibits the largest value, while IPS-60 shows similar CS to that in P-60. Such phenomenon indicates that $\mathrm{Cu}-\mathrm{Co}-\mathrm{O}$ thin film has the definitely catalytic effect on $\mathrm{CS}$ and SSM plays a minor role. Compared with the result that SSM plays the main catalytic effect on the toluene conversion in the first stage, $\mathrm{Cu}$ Co-O thin film plays the main catalytic effect in the second stage, no matter on the toluene conversion or the $\mathrm{CO}_{2}$ selectivity.

\subsection{Partially-located pattern}

For the DBD reactor with 200-mm plasma region, one piece of round $\mathrm{SSM}$ or $\mathrm{Cu}-\mathrm{Co}-\mathrm{O} / \mathrm{SSM}$ with the diameter of $60 \mathrm{~mm}$, has to be partially located in the center of the plasma region. Fig. 10 and 11 illustrate the TC and DTC, as well as CS in various configurations, respectively. As shown in Fig. 10b, DTC presents only one peak for P-200, IPS-200 and IPC-200, indicating that the toluene abatement process presents onestage characteristics. It is different from the two-stage characteristics for the $60-\mathrm{mm} \mathrm{DBD}$ reactor. In P-200 configuration, toluene starts to convert at $3 \mathrm{~J} / \mathrm{L}$, and achieves $100 \%$ conversion at $8 \mathrm{~J} / \mathrm{L}$. The $50 \%$ conversion is speculated to be achieved at $4 \mathrm{~J} / \mathrm{L}$, as shown in Fig. 9. In IPS-200, toluene starts to convert at $2 \mathrm{~J} / \mathrm{L}$, and achieves $50 \%$ and $100 \%$ conversion at 3 and $5 \mathrm{~J} / \mathrm{L}$, as shown in Fig. 9, respectively. TC profile in the IPC-200 configuration is similar to that in the IPS-200, which demonstrates that the SSM addition benefits for toluene conversion instead of $\mathrm{Cu}-\mathrm{Co}-\mathrm{O}$ film. In the 200-mm-plasma-region DBD reactor, the concentration of $\mathrm{CO}_{2}$ keeps larger than that of $\mathrm{CO}$ for all the 200-

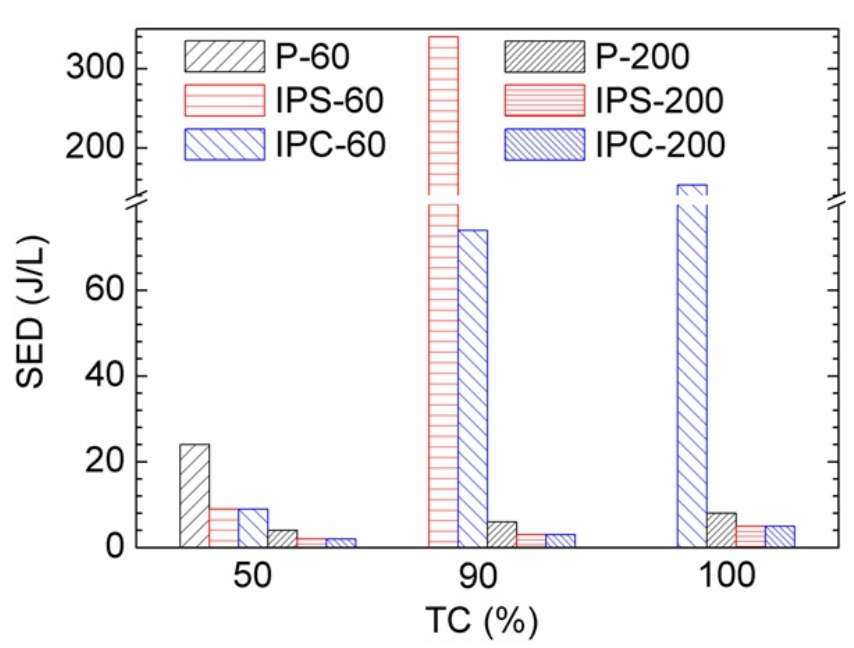

Fig. 9 SEDs in various configurations as TC achieves 50\%, 90\% and $100 \%$. mm plasma region configurations. CS keeps $64 \%$ as the SED increases, till the toluene consumes completely, as shown in Fig. 12. SSM and $\mathrm{Cu}-\mathrm{Co}-\mathrm{O}$ thin film have little effect on the $\mathrm{CO}_{2}$ selectivity.

\subsection{Proposed mechanism}

The intermediates produced during the removal of toluene were listed in

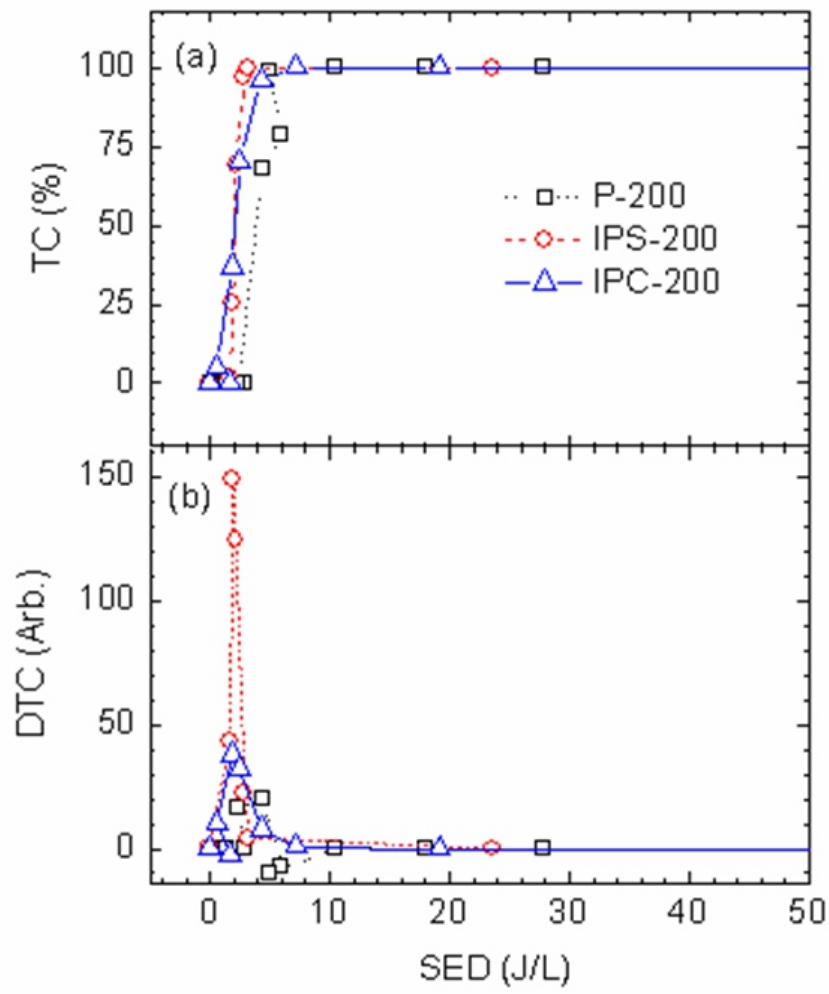

Fig. 10 (a) Toluene conversions and (b) derivatives of toluene conversion in various configurations with $200 \mathrm{~mm}$ plasma region.

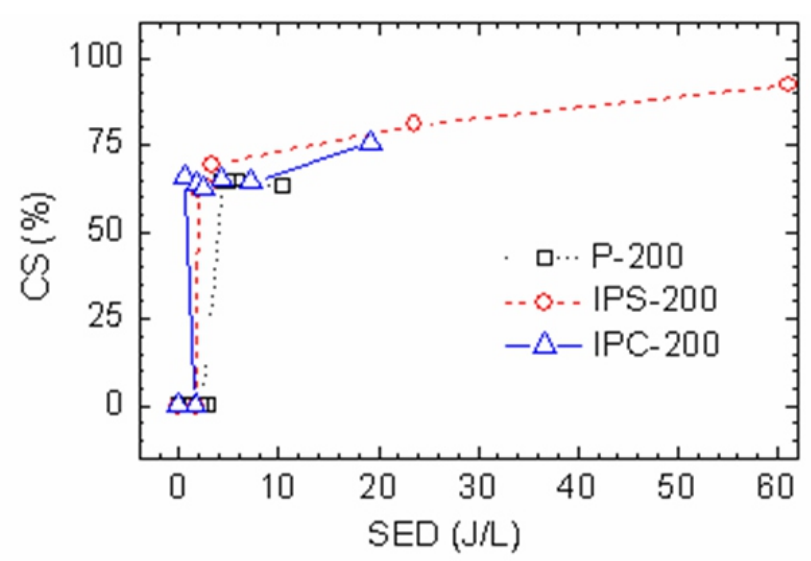

Fig. $11 \mathrm{CSs}$ in various configurations with $200 \mathrm{~mm}$ plasma region.

Table 3 Electrical resistivities and conductivities of the SSM and Cu-Co-O/SSM.

\begin{tabular}{ccc}
\hline Parameters & SSM & Cu-Co-O/SSM \\
\hline Resistivity $(\Omega \cdot \mathrm{m})$ & 2.240 & 5.670 \\
Conductivity $(1 /(\Omega \cdot \mathrm{m}))$ & 0.446 & 0.176 \\
\hline
\end{tabular}


Table 4 The intermediates detected in the experiment.

\begin{tabular}{|c|c|c|c|}
\hline No. & Name & Molecular formula & Molecular structure \\
\hline 1 & Methane & $\mathrm{CH}_{4}$ & \\
\hline 2 & Ethanal & $\mathrm{C}_{2} \mathrm{H}_{4} \mathrm{O}$ & \\
\hline 3 & 1,3-butadiene & $\mathrm{C}_{4} \mathrm{H}_{6}$ & \\
\hline 4 & Acetone & $\mathrm{C}_{3} \mathrm{H}_{6} \mathrm{O}$ & \\
\hline 5 & Isopropanol & $\mathrm{C}_{3} \mathrm{H}_{8} \mathrm{O}$ & \\
\hline 6 & Benzaldehyde & $\mathrm{C}_{7} \mathrm{H}_{6} \mathrm{O}$ & \\
\hline 7 & Acetophenone & $\mathrm{C}_{8} \mathrm{H}_{8} \mathrm{O}$ & \\
\hline 8 & Phenol & $\mathrm{C}_{6} \mathrm{H}_{6} \mathrm{O}$ & \\
\hline 9 & P-methylphenol & $\mathrm{C}_{7} \mathrm{H}_{8} \mathrm{O}$ & \\
\hline 10 & M-isopropylphenol & $\mathrm{C}_{8} \mathrm{H}_{12} \mathrm{O}$ & \\
\hline 11 & Phenylpropane & $\mathrm{C}_{9} \mathrm{H}_{12}$ & \\
\hline 12 & Biphenyl & $\mathrm{C}_{12} \mathrm{H}_{10}$ & \\
\hline 13 & Bibenzyl & $\mathrm{C}_{14} \mathrm{H}_{14}$ & \\
\hline 14 & Naphthalene & $\mathrm{C}_{10} \mathrm{H}_{8}$ & \\
\hline 15 & Methylnaphthalene & $\mathrm{C}_{11} \mathrm{H}_{10}$ & \\
\hline 16 & Indene & $\mathrm{C}_{9} \mathrm{H}_{8}$ & \\
\hline 17 & Benzofuran & $\mathrm{C}_{8} \mathrm{H}_{6} \mathrm{O}$ & \\
\hline 18 & $\begin{array}{c}\text { Hydrogenated } \\
\text { benzofuran }\end{array}$ & $\mathrm{C}_{8} \mathrm{H}_{8} \mathrm{O}$ & \\
\hline
\end{tabular}


table 4. Since the inlet toluene concentration was as low as $231 \mathrm{ppm}$, the mole fractions of the intermediates were too low to be quantified by the GC or GC-MS with the detection limit of several ppm. It is difficult to get the rule from the mole fraction data of the intermediates. But it did not inhibit the speculation of the toluene removal mechanism.

Fig. 13 shows the mechanism of toluene removal in the DBD reactor coupled with binary oxide thin film. As the SED is lower than $20 \mathrm{~J} / \mathrm{L}$, plasma discharge plays the main role for the abatement of toluene. The mechanism is dominated by the gas phase reactions. SSM addition could influence the plasma discharge characteristics in the reactor by reducing the effective discharge gap. The $\mathrm{Cu}-\mathrm{Co}-\mathrm{O}$ thin film does not change the conductive property of SSM definitely. Therefore, toluene conversion and $\mathrm{CO}_{2}$ selectivity in the two configurations are similar. The concentrations of $\mathrm{CO}$ and $\mathrm{CO}_{2}$ would equally increase as that of the active oxygen increases resulting from the SED increases. As the discharge power becomes larger, concentrations of active oxygen

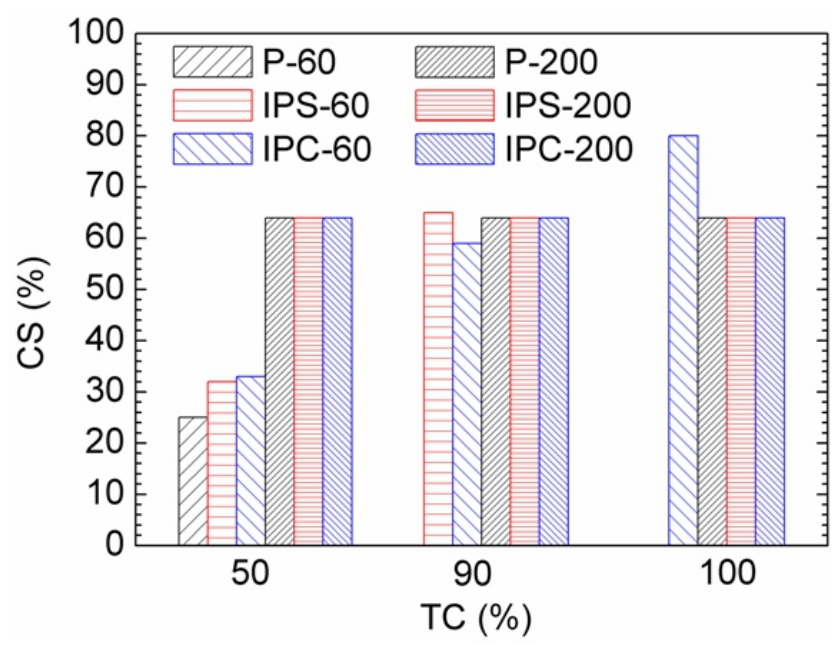

Fig. 12 CSs in various configurations as the toluene conversion achieve $50 \%, 90 \%$ and $100 \%$. and active hydrocarbon pieces tend to increase. The concentrations of $\mathrm{CO}$ and $\mathrm{CO}_{2}$ would be increased much. More active oxygen results in the production of $\mathrm{CO}_{2}$ from $\mathrm{CO}$. The $\mathrm{CO}_{2}$ selectivity increases. SSM could change the dischargeplay characteristics to enhance the toluene removal. Since the $\mathrm{Cu}-\mathrm{Co}-\mathrm{O}$ film could provide the catalytic surface, and the lattice oxygen atom would be activated to join the surface reaction, the abatement of toluene could be improved by $\mathrm{Cu}-\mathrm{Co}-\mathrm{O}$ film.

\subsection{Comparison}

\subsubsection{Fully-and partially-located pattern}

Compared the toluene conversion between fully- and partially-located pattern, the TC could achieve $100 \%$ at much lower $\mathrm{U}_{\mathrm{i}}$, i.e. SED. Longer plasma region leads to higher toluene conversion at the similar SED. In the 60-mm-plasma-region DBD reactor, the CS was about 30\%. While CSs in P-200, IPS-200 and IPC-200 are similar to be $64 \%$. Longer plasma region leads to larger CS as well. Since the length of the catalyst is similar no matter for the fully or partially catalyst located pattern, the difference of toluene conversion characteristics between the two kinds of configurations mainly results from the different length of the plasma region. The flowrate of the mixed gas keeps similar for the different configuration. Therefore, the residence times of the toluene and $\mathrm{O}_{2}$ are decided by the plasma region length. For P-200 and P-60 configurations, the residence times are 1.23 and $0.37 \mathrm{~s}$, respectively. Longer residence time, means the longer decomposition and reaction times in the plasma region, which brings the more exhaustive chemical reaction of the active species. Increasing the length of the plasma region benefits to the toluene removal for the plasma-catalyst system.

As shown in Fig. 12, the CSs are similar in P-200, IPS-200 and IPC-200 as the toluene conversion achieves $50 \%, 90 \%$ and $100 \%$, respectively. It means that adding $\mathrm{SSM}$ or $\mathrm{Cu}-\mathrm{Co}-\mathrm{O} / \mathrm{SSM}$ in the middle of the plasma region has no effect on the $\mathrm{CO}_{2}$ selectivity. Neglecting the heterogeneous reactions on the silica and SSS surface, in the only plasma configuration, $\mathrm{CO}$ and $\mathrm{CO}_{2}$ are mainly produced from the chemical reactions in the gas phase. In the IPS and IPC configurations, $\mathrm{CO}$ and $\mathrm{CO}_{2}$ are mainly produced through two ways: reactions in gas phase and heterogeneous reactions on the surface of SSM or $\mathrm{Cu}-\mathrm{Co}-\mathrm{O}$

Table 5 Comparison between this work and previous work.

\begin{tabular}{|c|c|c|c|c|c|c|c|c|c|}
\hline Catalyst & Support & $\begin{array}{c}\text { Active } \\
\text { component }\end{array}$ & $\begin{array}{l}\text { Quantity of } \\
\text { the catalyst }\end{array}$ & $\begin{array}{c}\text { Percentage } \\
\text { of the active } \\
\text { component } \\
(w t \%)\end{array}$ & Plasma & $\begin{array}{l}\text { Residen } \\
\text { ce time }\end{array}$ & $\begin{array}{l}\mathrm{SED}(80 \% \\
\text { toluene } \\
\text { conversion, } \\
\mathrm{J} / \mathrm{L})\end{array}$ & $\begin{array}{c}\mathrm{SED}(80 \% \\
\mathrm{CO}_{2} \\
\text { selectivity) }\end{array}$ & Ref. \\
\hline $\begin{array}{c}\text { 60Co-MCM-41_i } \\
\mathrm{mp}\end{array}$ & Molecular sieve & Co & $100 \mathrm{mg}$ & 3.45 & IPC & --- & 162 & N.A. ${ }^{a}$ & {$[10]$} \\
\hline $\mathrm{CuO}-\mathrm{MnO}_{2} / \mathrm{TiO}_{2}$ & $\mathrm{TiO}_{2}$ pellet & $\mathrm{CuO}, \mathrm{MnO}_{2}$ & $10 \mathrm{~g}$ & 9.8 & PPC & $0.25 \mathrm{~s}$ & 2 & --- & [13] \\
\hline $\begin{array}{c}\mathrm{MnOx} / \mathrm{Al}_{2} \mathrm{O}_{3} / \text { nick } \\
\text { el foam }\end{array}$ & $\mathrm{Al}_{2} \mathrm{O}_{3} /$ nickel foam & $\mathrm{MnOx}$ & $15 \mathrm{~cm}^{3}$ & $30^{\mathrm{a}}$ & IPC & $0.02 \mathrm{~s}^{\mathrm{b}}$ & 255 & $<250$ & {$[30,31]$} \\
\hline $\begin{array}{c}\mathrm{FeOx} / \mathrm{Al}_{2} \mathrm{O}_{3} / \text { nicke } \\
1 \text { foam } \\
\end{array}$ & $\mathrm{Al}_{2} \mathrm{O}_{3} /$ nickel foam & $\mathrm{FeOx}$ & $15 \mathrm{~cm}^{3}$ & --- & IPC & $0.02 \mathrm{~s}^{\mathrm{b}}$ & 240 & $<195$ & [30] \\
\hline $\begin{array}{c}\mathrm{CoOx} / \mathrm{Al}_{2} \mathrm{O}_{3} / \text { nick } \\
\text { el foam }\end{array}$ & $\mathrm{Al}_{2} \mathrm{O}_{3} /$ nickel foam & $\mathrm{CoOx}$ & $15 \mathrm{~cm}^{3}$ & --- & DBD & $0.02 \mathrm{~s}^{\mathrm{b}}$ & 278 & $<175$ & [30] \\
\hline $\mathrm{Cu}-\mathrm{Co}-\mathrm{O} / \mathrm{SSM}$ & SSM & $\mathrm{Cu}-\mathrm{Co}-\mathrm{O}$ & $0.44 \mathrm{~g}$ & 0.7 & IPC-200 mm & $1.23 \mathrm{~s}$ & 4 & 20 & This work \\
\hline
\end{tabular}

Note: ${ }^{\text {a }}$ N.A. means not achieved; ${ }^{\mathrm{b}}$ calculated by the ratio in Ref $31 ;{ }^{\mathrm{c}}$ calculated by the $150 \mathrm{~mm}$ effective length in Ref. 31 divided by the $450 \mathrm{~m} / \mathrm{min}$ gas flow rate in Ref. 30; 
thin film. The plasma discharge in the similar reactor has no selectivity effect on the production of COx. However, surface of the catalyst could provide the absorption site for the production of $\mathrm{CO}_{2}$ from $\mathrm{CO}$. The similarity of the $\mathrm{CO}_{2}$ selectivity in the three configurations indicated that surface of SSM and Cu-Co-O thin film/SSM has no effect on the $\mathrm{CO}_{2}$ selectivity. As the input voltage of the power is in the scale of $0-10 \mathrm{~V}$, $\mathrm{Cu}-\mathrm{Co}-\mathrm{O}$ thin film has no effect on the abatement of toluene.
Improvement induced by adding SSM results from the influence on the characteristics of the plasma discharge by reducing the discharge gap. As the input voltage of the power increases above $20 \mathrm{~V}$, the CS increase as well. The $\mathrm{Cu}-\mathrm{Co}-\mathrm{O}$ thin film starts to be like a catalyst. The reason might be that the concentrations of active hydrocarbon species and oxygen increase as the discharge power increases. The absorption of oxygen group are enhanced and the $\mathrm{CO}$ reacting with oxygen to produce $\mathrm{CO}_{2}$ are improved.

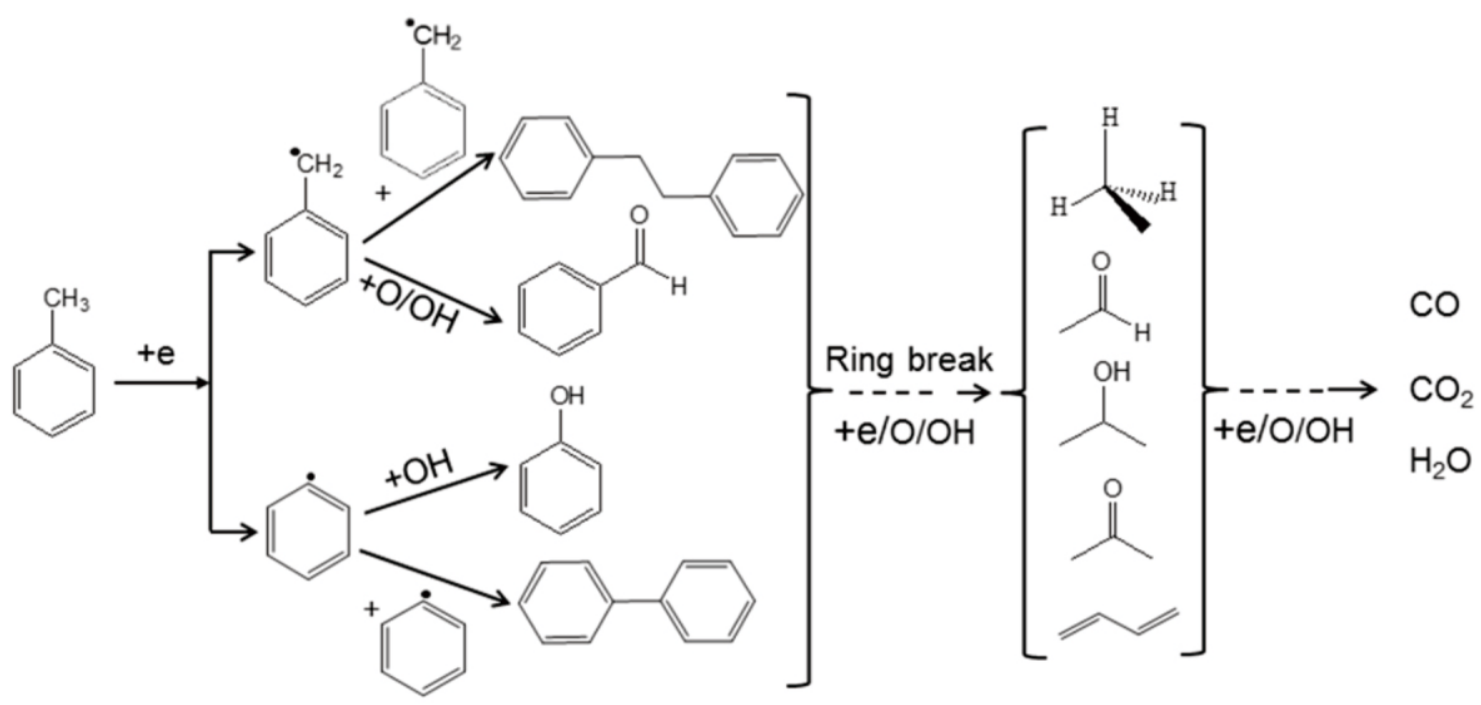

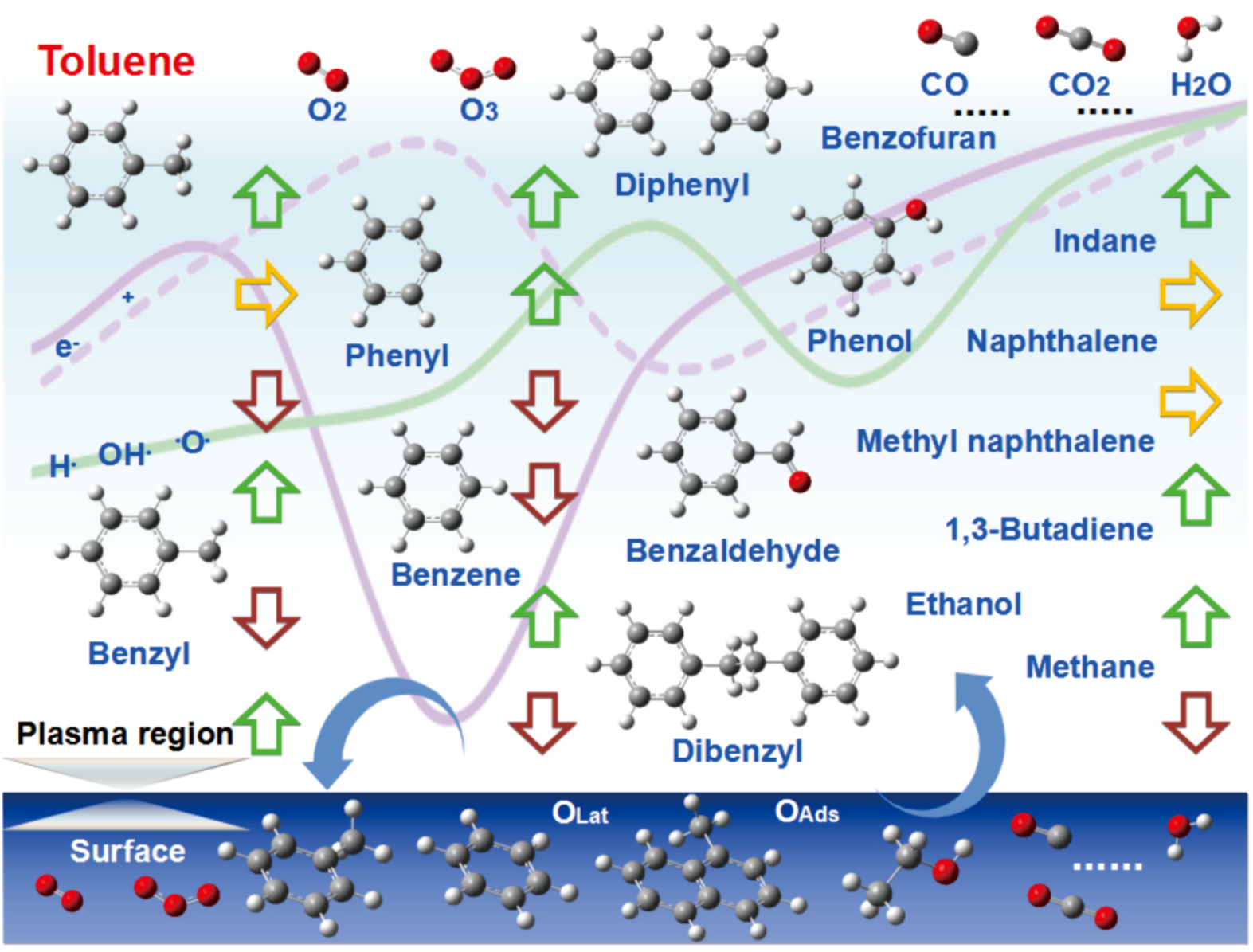

Fig. 13 Proposed mechanism of the gas (upper) and surface (bottom) reaction. 


\subsubsection{The present and previous work}

As listed in Table 5, compared with the previous work, the SEDs in IPC-60 and IPC-200 are 67 and $4 \mathrm{~J} / \mathrm{L}$ as the toluene conversion is $80 \%$. The SEDs in IPC-60 and IPC-200 are 152 and $20 \mathrm{~J} / \mathrm{L}$ as the $\mathrm{CO}_{2}$ selectivity is $80 \%$. These are much lower than those in the previous studies for the IPC configurations. The quantity of the active component in this work is about $3.09 \mathrm{mg}$, which is less than that in the previous studies. The lower SED and less active component means the better characteristics of the plasma-catalysis reactor in the present work. The shorter discharge gap and the high purity of the metal oxide crystals might be the main reason.

\section{Conclusion}

This work reports the effect of $\mathrm{Cu}-\mathrm{Co}$ oxide thin film, coated on stainless steel mesh, on the conversion of toluene in the non-thermal plasma reactor without additional heating. Six configurations, P-60, IPS60, IPC-60, P-200, IPS-200 and IPC-200, have been used for the comparison studies. Two-stage abatement exits as the discharge power increases for the fully-located pattern. SSM plays the main catalytic role by acting an electrode in the first stage, while the $\mathrm{Cu}-\mathrm{Co}-\mathrm{O}$ thin film joins the catalytic activity by providing a reactive surface in the second stage. For the partially-located pattern, one-stage abatement exits as the discharge power increases. SSM addition, with or without $\mathrm{Cu}-\mathrm{Co}-\mathrm{O}$ thin film, in the center of the plasma region, could equally improve the toluene conversion. SSM play the main catalytic role but $\mathrm{Cu}-\mathrm{Co}-\mathrm{O}$ thin film has little effect on the toluene conversion. Therefore, the toluene removal is a gas reaction converting to surface reaction process. Specific energy density and locating pattern would influence the effect of $\mathrm{Cu}-\mathrm{Co}-\mathrm{O}$ thin film coated on SSM. This work is meaningful to the employment of binary oxide thin film with high efficiency on the conversion of toluene for practical industrial application.

\section{Acknowledgments}

This work was mainly funded by the the Ministry of Science and Technology of China (2017YFA0402800), National Natural Science Foundation of China (No. 51888103/51976216), National Key R\&D Program of China, Innovation Guidance foundation of Institute of Engineering Thermophysics, Chinese Academy of Sciences and Recruitment Program of Global Youth Experts. MW acknowledges the support of CAS-TWAS Presidents' Fellowship. AEK is grateful for the support of Chinese Academy of Sciences for senior international scientists within the framework of PIFI program.

\section{References}

1. A. L. Bolden, C. F. Kwiatkowski and T. Colborn, Environ. Sci. Technol., 2015, 49, 11984-11989.

2. Z. Bo, H. Hao, S. Yang, J. Zhu, J. Yan and K. Cen, Appl. Surf. Sci., 2018, 436, 570-578.
3. J. Wu, Q. Xia, H. Wang and Z. Li, Appl. Catal. B Environ., 2014, 156, 265-272.

4. A. M. Vandenbroucke, R. Morent, N. De Geyter and C. Leys, J. Adv. Oxid. Technol., 2012, 15, 232-241.

5. M. Ferrandon, J. Carno, S. Jaras and E. Bjornbom, Appl. Catal. A Gen., 1999, 180,153-161.

6. S. Delagrange, L. Pinard and J. M. Tatibouet, Appl. Catal. B Environ., 2006, 68, 92-98.

7. Y. F. Guo, D. Q. Ye, K. F. Chen and J. C. He, Catal. Today, 2007, 126, 328-337.

8. Z.Y. Tian, P. H. T. Ngamou, V. Vannier, K. Kohse-Hoinghaus and N Bahlawane, Appl. Catal. B Environ., 2012, 117, 125-134.

9. B. Wang, C. Chi, M. Xu, C. Wang and D. Meng, Chem. Eng. J., 2017, 322, 679-692.

10. X. Xu, J. Wu, W. Xu, M. He, M. Fu, L. Chen, A. Zhu and D. Ye, Catal Today, 2017, 281, 527-533.

11. H. H. Kim, A. Ogata and S. Futamura, J. Phys. D: Appl. Phys., 2005, 38, 1292-1300.

12. C. Subrahmanyam, A. Magureanu, A. Renken and L. Kiwi-Minsker, Appl. Catal. B Environ., 2006, 65, 150-156.

13. J. Van Durme, J. Dewulf, W. Sysmans, C. Leys and H. Van Langenhove, Appl. Catal. B Environ., 2007, 74, 161-169.

14. J. O. Chae, V. Demidiouk, M. Yeulash, I. C. Choi and T. G. Jung, IEEE Trans. Plasma Sci., 2004, 32, 493-497.

15. R. Zhu, Y. Mao and L. Jiang, J. Chen, Chem. Eng. J., 2015, 279, 463-471.

16. C. He, L. Cao, X. Liu, W. Fu and J. Zhao, Int. J. Environ. Sci. Tech., 2015, 12, 3531-3540.

17. M. J. Garcia-Fernandez, M. M. Pastor-Blas, F. Epron and A. SepúlvedaEscribano, Appl. Catal. B Environ., 2018, 225, 162-171.

18. Y. Feng, P. M. Rao, D. R. Kim and X. Zheng, Proc. Combust. Inst., 2011, 33, 3169-3175.

19. M. F. Zheng, D. Q. Yu, L. J. Duan, W. H. Yu and L. Huang, Catal. Commun., 2017, 100, 187-190

20. L. Mohammadi, E. Bazrafshan, M. Noroozifar, A. Ansari-Moghaddam, F. Barahuie and D. Balarak, J. Chem., 2017, 2017, 2069519.

21. E. C. Neyts and A. Bogaerts, J. Phys. D: Appl. Phys., 2014, 47, 224010

22. W. Wang, H. H. Kim, K. Van Laer and A. Bogaerts, Chem. Eng. J., 2018, 334, 2467-2479.

23. W. Somers, A. Bogaerts, A. C. T. van Duin and E. C. Neyts, J. Phys. Chem. C, 2012, 116, 20958-20965.

24. Y. R. Zhang, K. Van Laer, E. C. Neyts, A. Bogaerts, Appl. Catal. B Environ., 2016, 185, 56-67.

25. H. L. Chen, H. M. Lee, S. H. Chen, M. B. Chang, S. J. Yu and S. N. Li, Environ. Sci. Technol., 2009, 43, 2216-2227.

26. S. B. Ay and N. K. Perkgoz, J. Nanomater, 2015, 2015, 257547.

27. D. W. Lee and B. R. Yoo, J. Ind. Eng. Chem., 2014, 20, 3947-3959.

28. P. M. Kouotou, Z. Y. Tian, H. Vieker, A. Beyer, A. Goelzhaeuser and K. Köhse-Hoeinghaus, J. Mater. Chem. A, 2013, 1, 10495-10504.

29. G. F. Pan, S. B. Fan, J. Liang, Y. X. Liu and Z. Y. Tian, Rsc Adv., 2015, 5,42477-42481.

30. Y. Guo, X. Liao, M. Fu, H. Huang and D. Ye, J. Environ. Sci., 2015, 28, $187-$ 194

31. Y. F. Guo, D. Q. Ye, K. F. Chen, J. C. He and W. L. Chen, J. Mol. Catal. A. Chem., 2006, 245, 93-100.

Publisher's Note Engineered Science Publisher remains neutral with regard to jurisdictional claims in published maps and institutional affiliations. 